\title{
Genetic parameters for hoof lesions and their relationship with feet and leg traits in Canadian Holstein cows
}

\author{
N. Chapinal, ${ }^{*}{ }^{1}$ A. Koeck, $\ddagger$ A. Sewalem,§\# D. F. Kelton, ${ }^{*}$ S. Mason, II G. Cramer, $\Uparrow$ and F. Miglior§\# \\ ${ }^{*}$ Department of Population Medicine, University of Guelph, ON, Canada, N1G 2W1 \\ †Animal Welfare Program, University of British Columbia, BC, Canada, V6T $1 Z 4$ \\ †Centre for Genetic Improvement of Livestock, University of Guelph, Guelph, ON, Canada, N1G 2W1 \\ $\S$ Guelph Food Research Centre, Agriculture and Agri-Food Canada, Guelph, ON, Canada, N1G 5C9 \\ \#Canadian Dairy Network, Guelph, ON, Canada, N1K 1E5 \\ IIAlberta Milk, Edmonton, AB, Canada, T6X 1H1 \\ TCramer Mobile Bovine Veterinary Services, Stratford, ON, Canada, N5A 7L5
}

\section{ABSTRACT}

The objectives were (1) to estimate the genetic parameters and breeding values of hoof lesions, (2) to estimate the phenotypic effect of each feet and legs conformation traits on hoof lesions, and (3) to estimate genetic correlations between hoof lesions with feet and legs conformation traits. The presence or absence of specific hoof lesions was recorded for each hoof. Lesions were classified into infectious (digital and interdigital dermatitis, foot rot, and heel erosion), horn (sole and toe ulcer, sole hemorrhage, and white line disease), and other lesions (interdigital hyperplasia, fissures, thin soles, and corkscrew claw). A total of 34,905 hoof health records from 27,179 cows and 365 herds, collected by 18 different hoof-trimmers in Ontario, Alberta, and British Columbia, were analyzed using linear animal models. In addition, 5 feet and leg conformation traits (foot angle, heel depth, bone quality, rear leg side view, and rear leg rear view) and locomotion from primiparous cows were considered $(\mathrm{n}=11,419$ and 6,966 cows, for conformation traits and locomotion, respectively). At least one lesion was found in nearly $40 \%$ of the hoof trimming records. The heritability estimates for hoof lesions ranged from 0.01 for front horn lesions to 0.09 for rear infectious lesions. Despite the low heritability estimates, we observed large variability in sire estimated breeding value (EBV) for resistance to hoof lesions. Positive genetic correlations were found between the occurrence of front and rear infectious lesions (0.77) and between front and rear horn lesions (0.61), but not between infectious and horn lesions (0.08). For most of the conformation traits, low scores were phenotypically associated with higher incidence of horn lesions, whereas we found no evidence of a phenotypic effect of feet and leg traits on infectious lesions. The heritability

Received August 21, 2012.

Accepted January 5, 2013.

${ }^{1}$ Corresponding author: nchapinal@yahoo.com of the conformation traits ranged from 0.04 for rear leg rear view to 0.22 for bone quality, whereas that for locomotion was 0.03 . The genetic correlations between hoof lesions and conformation traits were low to moderate, yet most of the estimates were associated with high standard errors. In conclusion, although hoof lesions are lowly heritable traits, sufficient genetic variation exists (as evidenced by large variability in sire EBV) for genetic improvement through direct selection in the long term. Standardization of hoof health data collection is encouraged.

Key words: infectious lesion, horn lesion, locomotion, genetic parameter

\section{INTRODUCTION}

Maintaining hoof health is a challenge in modern dairy herds. Recent studies in North America and Europe have reported prevalences of 40 to $70 \%$ of the cows with at least one hoof lesion (Manske et al., 2002; Sogstad et al., 2005; Buch et al., 2011). Hoof lesions compromise the welfare of animals (Whay et al., 2003) and can result in reduced milk yield (Warnick et al., 2001; Amory et al., 2008), reduced fertility (Hernández et al., 2001; Meléndez et al., 2003), and increased risk of premature culling (Rajala-Schultz and Gröhn, 1999; Booth et al., 2004). Many factors affect the risk of hoof lesions, including environmental factors, such as the design of the facilities and management practices (Barker et al., 2009; Cook and Nordlund, 2009; Cramer et al., 2009), and genetics (van der Waaij et al., 2005; van der Linde et al., 2010; Buch et al., 2011). Therefore, the incidence of hoof lesions can be reduced by improved management practices and genetic selection.

Hoof lesions are heritable and, although estimated heritability estimates are low (ranging from 0.01 to 0.20; Koenig et al., 2005; van der Waaij et al., 2005; van der Linde et al., 2010), long-term improvement of hoof health can be achieved by direct genetic selection 
for hoof lesion resistance. Several studies showed only low to moderate correlations between hoof lesions and feet and leg conformation traits (Onyiro et al., 2008; Laursen et al., 2009; van der Linde et al., 2010). As a result, indirect genetic selection for hoof lesion resistance has not been very effective. However, genetic correlations differ depending on the definition of the conformation traits and the population studied. Most of the studies on genetic parameters for hoof lesions have been conducted in Europe (Laursen et al., 2009; van der Linde et al., 2010; Buch et al., 2011). Thus, the potential of hoof lesion data for direct genetic selection for hoof health and of conformation data to predict and indirectly select for hoof health in North America has to be investigated.

Hoof lesions have traditionally been classified according to their etiology and pathogenesis (Greenough, 2007) into infectious or partly infectious lesions (e.g., digital and interdigital dermatitis, foot rot, and heel erosion), mostly related to environmental hygiene, and horn lesions (e.g., sole and toe ulcer, sole hemorrhage, and white line disease), mostly caused by metabolic or mechanical factors. Previous studies reported strong genetic correlations between specific lesions within each category (van der Waaij et al., 2005; van der Linde et al., 2010; Buch et al., 2011) but, to our best knowledge, genetic parameters for these 2 categories have not been estimated. Thus, the objectives of the current study were (1) to estimate the genetic parameters and breeding values of hoof infectious and horn lesions, (2) to estimate the phenotypic effect of each feet and legs conformation trait on hoof lesions, and (3) to estimate genetic correlations between hoof lesions with feet and legs conformation traits.

\section{MATERIALS AND METHODS}

\section{Data Description}

Hoof lesions were recorded by hoof trimmers from March 2004 to July 2005 in Ontario, from June 2009 to October 2011 in Alberta, and from October 2010 to October 2011 in British Columbia, Canada. Hoof trimmers visited farms according to the herd standard hooftrimming protocol. Commonly, cows were routinely hoof trimmed once or twice per lactation, or if clinical signs were detected at the time of the hoof trimmer's visit. However, the reason for hoof trimming was not recorded for logistic reasons (i.e., farmers would likely have to prepare 2 separate lists of cows for the hoof trimmer, and the hoof trimmer would have to make a distinction when entering the data). The data recorded in Ontario were part of an observational study (Cramer et al., 2008), whereas the data recorded in Alberta and
British Columbia were part of the ongoing Alberta Dairy Hoof Health Project (details on which can be found at www.hoofhealth.ca). In brief, 7 hoof trimmers in Alberta and 6 hoof trimmers in British Columbia were trained to use a rugged touch-screen computerized lesion recording system (Hoof Supervisor, Dresser, WI). This system facilitates the routine and consistent collection of hoof lesion data, based on lesion descriptions proposed by the International Lameness Committee, a global collaboration of researchers, veterinarians, academics, and hoof-trimming professionals.

As the majority of the cows (68\%) were only hoof trimmed once during the same lactation, only the first hoof-trimming session was included in the analyses, similar to the methods of Buch et al. (2011). Furthermore, a preliminary analysis showed similar results when genetic parameters were estimated using the last hoof-trimming session of the lactation. Records taken more than $500 \mathrm{~d}$ after calving were discarded. Four seasons of hoof trimming were defined: January to March, April to June, July to September, and October to December, and the variable herd-year-season was created. The herd-year-season categories with fewer than 5 hoof-trimming records were discarded. The final data set consisted of 34,905 hoof-trimming records from 27,179 cows from 365 herds, collected by 18 different hoof trimmers.

Hoof lesions were recorded as presence or absence of specific hoof lesions in each hoof: sole and toe ulcer, sole hemorrhage, white line disease (separation and abscesses), digital and interdigital dermatitis, foot rot, heel erosion, interdigital hyperplasia, fissures, thin soles, and corkscrew claw. For the analyses, lesions were classified according to their etiology and pathogenesis (Greenough, 2007) into (1) infectious or partly infectious lesions (digital and interdigital dermatitis, foot rot, and heel erosion), (2) horn lesions, caused by metabolic or mechanical factors (sole and toe ulcer, sole hemorrhage, and white line disease), and (3) other lesions (interdigital hyperplasia, fissures, thin soles, and corkscrew claw). This classification was chosen to (a) give the study a practical approach, because there is no intention, in the near future, to develop a genetic evaluation system for each individual lesion trait, (b) prevent the misclassification of diseases that have similar etiology and pathogenesis and that can be hard to distinguish in routinely collected data sets, and (c) avoid the analysis of traits that are highly correlated as if they were independent traits. Nine hoof lesion binary traits $(0=$ no lesion, 1 = at least 1 lesion) were created at the cow level: (a) having at least one lesion in any hoof, (b) having at least one lesion in a front hoof, (c) having at least one lesion in a rear hoof, (d) having at least one infectious lesion in any hoof, (e) having at least one horn 
lesion in any hoof, (f) having at least one infectious lesion in a front hoof, $(\mathrm{g})$ having at least one infectious lesion in a rear hoof, $\mathrm{h}$ ) having at least one horn lesion in a front hoof, and (i) having at least one horn lesion in a rear hoof. Conformation data on feet and legs were obtained from the Canadian Dairy Network (Guelph, $\mathrm{ON})$. Conformation traits were routinely recorded by professional classifiers from Holstein Canada (Brantford, ON). Five conformation traits were considered: foot angle, heel depth, bone quality, rear leg side view, and rear leg rear view. In addition, locomotion score recorded during conformation evaluation in freestall barns since 2005 was available. All conformation traits were scored on a linear 1-to-9 scale. The optimum score for each trait is shown in Table 1. Conformation scores were transformed to normalize the data by using the procedure of Snell (1964). Only primiparous cows with conformation traits recorded within $365 \mathrm{~d}$ after calving were considered. In total, 11,419 primiparous cows had records on conformation traits, and of those, 6,966 cows had a locomotion score. The pedigree file was generated by tracing the pedigrees of cows 7 generations back, and contained the relationships of 119,484 animals.

\section{Models}

Data were analyzed with linear animal models using the average information-restricted maximum likelihood (AI-REML) procedure in the derivative-free approach to multivariate analysis (DMU) package (Madsen and Jensen, 2008). Although threshold models are, at least in theory, more appropriate to analyze binary traits, linear models were applied. In a previous study on Canadian health data, Neuenschwander (2010) found that the use of threshold models did not improve the goodness of fit compared with linear models. Besides, genetic correlations are reported to be correct for binary traits using linear models (e.g., Negussie et al., 2008).

Estimation of Genetic Parameters for Hoof Lesions. A first series of analyses was performed for the hoof lesions traits, including cows of all parities. The following models were carried out: (a) univariate model for occurrence of any lesion, (b) bivariate model between any front lesion and any rear lesion, (c) bivariate model between any infectious lesion and any horn lesion, and (d) 4-variate model between front infectious lesion, front horn lesion, rear infectious lesion, and rear horn lesion. The following linear animal model was applied to all lesion traits:

$$
\begin{aligned}
Y_{i j k l m n o}= & \mu+P_{i}+L T_{j}+H T_{k}+H Y S_{l} \\
& +a_{m}+p e_{n}+e_{i j k l m n o},
\end{aligned}
$$

where $Y_{i j k l m n o}$ is the observation for one of the lesion traits, $\mu$ is the overall mean, $P_{i}$ is the fixed effect of parity ( $i=1$ to $\geq 6), L T_{j}$ is the fixed effect of stage of lactation at trimming $(j=1$ to $16 ; 1=0$ to $30 \mathrm{~d}, 2=$ 31 to $60 \mathrm{~d}, \ldots, 15=421-450 \mathrm{~d}$, and $16=451-500 \mathrm{~d}$ after calving), $H T_{k}$ is the fixed effect of hoof trimmer ( $k$ $=1$ to 18), $H Y S_{l}$ is the fixed effect of herd-year-season of hoof trimming ( $l=1$ to 973$), a_{m}$ is the random additive genetic animal effect $(m=1$ to 119,484$), p e_{n}$ is the random permanent environmental effect $(n=1$ to $27,179)$, and $e_{i j k l m n o}$ is the random error term. Random effects were assumed to be normally distributed with zero means, and $\operatorname{Var}(a)=\mathbf{A} \sigma_{a}^{2}, \operatorname{Var}(p e)=\mathbf{I} \sigma_{p e}^{2}$, and $\operatorname{Var}(e)=\mathbf{I} \sigma_{e}^{2}$, where $\sigma_{a}^{2}, \sigma_{p e}^{2}$, and $\sigma_{e}^{2}$ are the additive genetic, permanent environmental, and residual variances, respectively, $\mathbf{I}$ is an identity matrix, and $\mathbf{A}$ is the additive genetic relationship matrix.

Estimation of Breeding Values. Sire EBV for resistance to infectious and horn lesions were obtained from the bivariate analysis including cows of all parities as described above (model [1]). Only sires with at least 20 daughters were considered. Estimated breeding values were reversed in sign. Thus, higher EBV indicated sires with daughters more resistant to lesions.

Phenotypic Association of Conformation Traits with Hoof Lesions. A second series of analyses was performed considering only primiparous cows with hoof lesions and conformation data (including locomotion).To assess the effect of each feet and leg

\begin{tabular}{|c|c|c|c|c|c|}
\hline Trait & Description of trait & Optimum & $\begin{array}{l}\text { Records } \\
\text { (no.) }\end{array}$ & Mean & SD \\
\hline Foot angle & Angle of toe $(1=$ extremely low, $9=$ extremely steep $)$ & 7 & 11,419 & 5.5 & 1.3 \\
\hline Rear leg side view & $\begin{array}{l}\text { Degree of curvature viewed from side }(1=\text { extremely straight, } 9= \\
\text { extremely curved) }\end{array}$ & 5 & 11,419 & 5.3 & 1.1 \\
\hline Rear leg rear view & $\begin{array}{l}\text { Turn of hock when viewed from rear }(1=\text { extremely hocked-in, } 9= \\
\text { extremely straight })\end{array}$ & 9 & 11,419 & 5.3 & 1.4 \\
\hline
\end{tabular}

Table 1. Description of conformation and locomotion traits in primiparous cows 
conformation trait on hoof lesions, an analysis was carried using the following animal model:

$$
\begin{aligned}
Y_{i j k l m n o}= & \mu+A G E_{i}+L T_{j}+H T_{k}+H Y S_{l} \\
& +F L T_{m}+a_{n}+e_{i j k l m n o},
\end{aligned}
$$

where $Y_{i j k l m n o}$ is the observation for one of the lesion traits, $\mu$ is the overall mean, $A G E_{i}$ is the fixed effect of age at calving $(i=1$ to $16 ; 1=<22$ mo, $2=22, \ldots$, $15=35 \mathrm{mo}, 16=>35 \mathrm{mo}), L T_{j}$ is the fixed effect of stage of lactation at trimming $(j=1$ to $16 ; 1=0$ to 30 $\mathrm{d}, 2=31$ to $60 \mathrm{~d}, \ldots, 15=421-450 \mathrm{~d}$, and $16=451-$ $500 \mathrm{~d}$ after calving), $H T_{k}$ is the fixed effect of hoof trimmer ( $k=1$ to 18$), H Y S_{l}$ is the fixed effect of herdyear-season of hoof trimming $(l=1$ to 973$), F L T_{m}$ is the fixed effect of each feet and leg conformation trait and locomotion ( $m=1$ to 9 ), $a_{n}$ is the random additive genetic animal effect ( $n=1$ to 119,484$)$, and $e_{i j k l m n o}$ is the random error term. Random effects were assumed to be normally distributed with zero means, and $\operatorname{Var}(a)=\mathbf{A} \sigma_{a}^{2}$ and $\operatorname{Var}(e)=\mathbf{I} \sigma_{e}^{2}$, where $\sigma_{a}^{2}$ and $\sigma_{e}^{2}$ are the additive genetic and residual variances, respectively, $\mathbf{I}$ is an identity matrix, and $\mathbf{A}$ is the additive genetic relationship matrix.

Genetic Association Between Hoof Lesions and Conformation Traits. A total of 13 bivariate models between infectious lesions, horn lesions, and feet and leg conformation traits (including locomotion) were performed. The following model was used for hoof lesions:

$$
\begin{gathered}
Y_{i j k l m n}=\mu+A G E_{i}+L T_{j}+H T_{k} \\
+H Y S_{l}+a_{m}+e_{i j k l m n},
\end{gathered}
$$

where $Y_{i j k l m n}$ is the observation for one of the lesion traits, $\mu$ is the overall mean, $A G E_{i}$ is the fixed effect of age at calving $(i=1$ to $16 ; 1=<22$ mo, $2=22, \ldots$, $15=35 \mathrm{mo}, 16=>35 \mathrm{mo}), L T_{j}$ is the fixed effect of stage of lactation at trimming $(j=1$ to $16 ; 1=0$ to 30 d, $2=31$ to $60 \mathrm{~d}, \ldots, 15=421-450 \mathrm{~d}$, and $16=451-$ $500 \mathrm{~d}$ after calving), $H T_{k}$ is the fixed effect of hoof trimmer ( $k=1$ to 18 ), $H Y S_{l}$ is the fixed effect of herdyear-season of hoof trimming ( $l=1$ to 887$), a_{m}$ is the random additive genetic animal effect $(m=1$ to $119,484)$, and $e_{i j k l m n}$ is the random error term. Random effects were assumed to be normally distributed with zero means, and $\operatorname{Var}(a)=\mathbf{A} \sigma_{a}^{2}$ and $\operatorname{Var}(e)=\mathbf{I} \sigma_{e}^{2}$, where $\sigma_{a}^{2}$ and $\sigma_{e}^{2}$ are the additive genetic and residual variances, respectively, $\mathbf{I}$ is an identity matrix, and $\mathbf{A}$ is the additive genetic relationship matrix.

The model for feet and leg conformation traits was

$$
Y_{i j k l m}=\mu+A G E_{i}+L C_{j}+H R C_{k}+a_{l}+e_{i j k l m},
$$

where $Y_{i j k l m}$ is the observation for one of the conformation traits, $\mu$ is the overall mean, $A G E_{i}$ is the fixed effect of age at calving ( $i=1$ to $16 ; 1=<22$ mo, $2=22$, $\ldots, 15=35 \mathrm{mo}, 16=>35 \mathrm{mo}), L C_{j}$ is the fixed effect of stage of lactation at classification $(j=1$ to $11 ; 1=0$ to $30 \mathrm{~d}, 2=31$ to $60 \mathrm{~d}, \ldots, 10=271$ to $300 \mathrm{~d}$, and 11 $=301$ to $365 \mathrm{~d}$ after calving), $H R C_{k}$ is the fixed effect of herd-round-classifier ( $k=1$ to 1,459$), a_{l}$ is the random additive genetic animal effect $(l=1$ to 119,484$)$, and $e_{i j k l m}$ is the random error term. Random effects were assumed to be normally distributed with zero means, and $\operatorname{Var}(a)=\mathbf{A} \sigma_{a}^{2}$ and $\operatorname{Var}(e)=\mathbf{I} \sigma_{e}^{2}$, where $\sigma_{a}^{2}$ and $\sigma_{e}^{2}$ are the additive genetic and residual variances, respectively, $\mathbf{I}$ is an identity matrix, and $\mathbf{A}$ is the additive genetic relationship matrix.

Table 2. Percentage of hoof trimming records with hoof lesions including all records and stratified by parity $(\mathrm{n}=27,179$ cows $)$

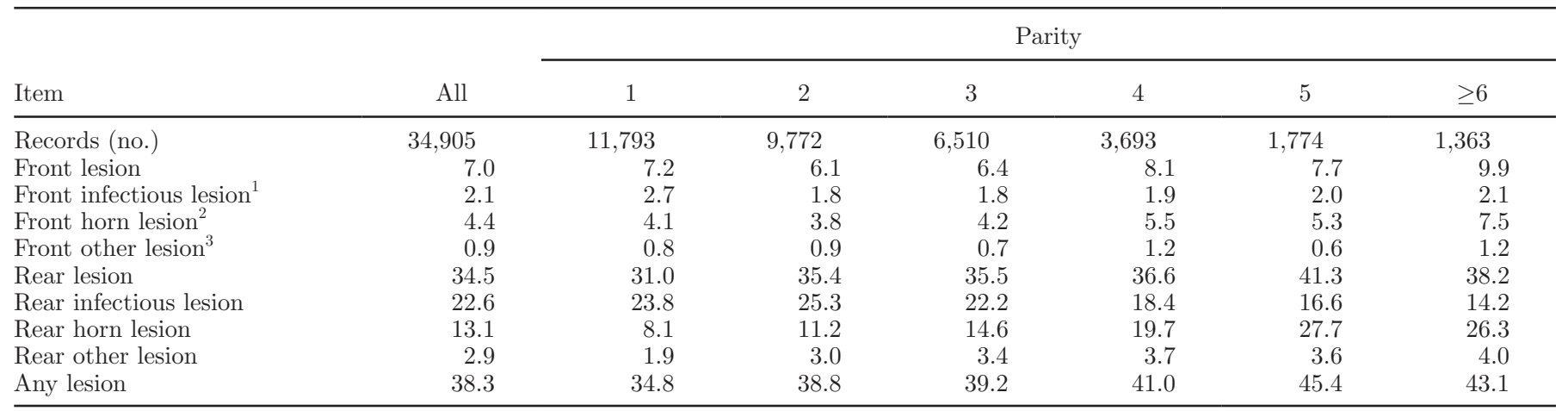

${ }^{1}$ Included digital and interdigital dermatitis, foot rot, and heel erosion.

${ }^{2}$ Included sole and toe ulcer, sole hemorrhage, and white line disease (separation and abscesses).

${ }^{3}$ Included interdigital hyperplasia, fissures, thin soles and corkscrew claw. 


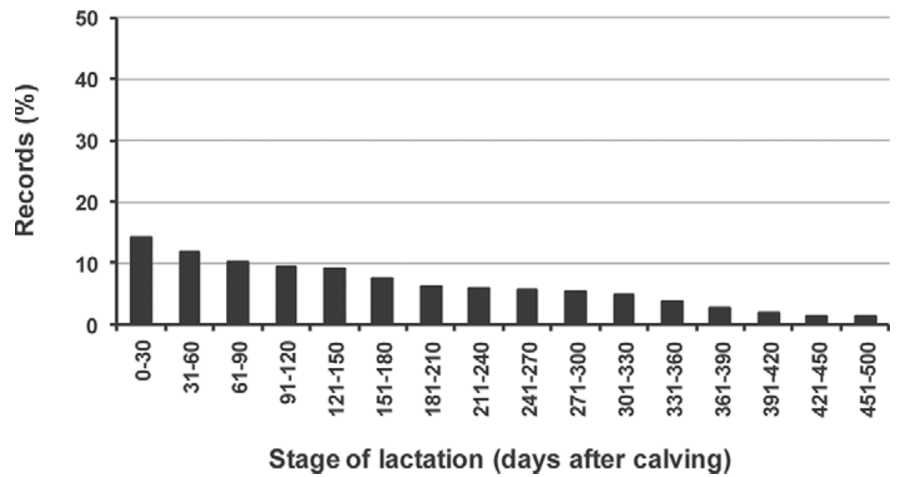

Figure 1. Percentage of hoof trimming records recorded at each stage of lactation ( $\mathrm{n}=34,905$ records from 27,179 cows).

\section{RESULTS AND DISCUSSION}

\section{Descriptive Analysis of Hoof Lesion Traits}

At least one lesion was found in nearly $40 \%$ of the hoof trimming records (Table 2), suggesting that modern dairy herds in North America could benefit from genetic selection for hoof health. Prevalence of hoof lesions (at least one lesion in 1 of the 4 hooves) in modern dairy herds varies across studies, ranging mostly from 40 to $70 \%$ (Manske et al., 2002; Sogstad et al., 2005; Buch et al., 2011). Lesions were more frequent in the rear hooves than in the front hooves, in agreement with the literature (Manske et al., 2002; Sogstad et al., 2005). This is likely because rear hooves are more exposed to manure and urine, and because of differences in the anatomy and mechanical function of the front and rear limbs that results in more strain exerted in the rear hooves (Phillips, 2002). Infectious lesions were the most common hoof disorder, in agreement with other studies that classified lesions similarly (Somers et al., 2003; Holzhauer et al., 2006). In the rear hooves, horn lesions increased with parity, whereas infectious lesions decreased. The prevalence of lesions in a herd and its

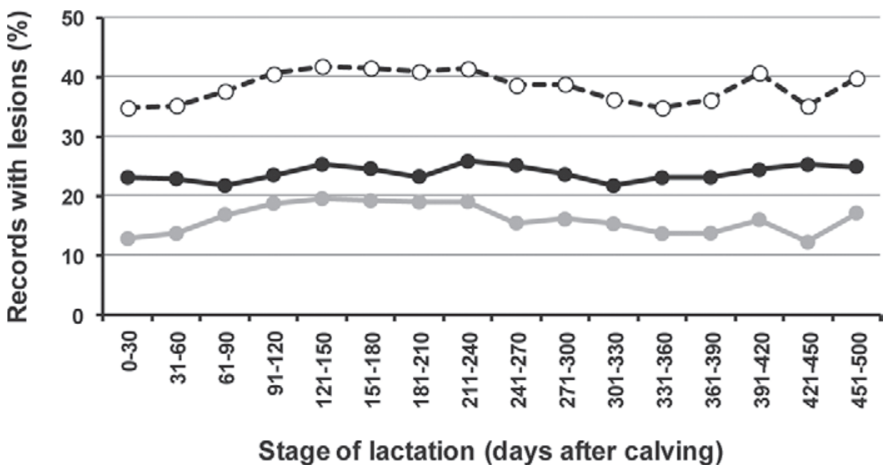

Figure 2. Percentage of hoof trimming records with any lesion (dashed line), infectious lesions (black line), and horn lesions (gray line) in at least one hoof at each stage of lactation $(\mathrm{n}=34,905$ records from 27,179 cows).

relationship with parity is influenced by culling practices as well as age-related factors. Repeated damage in the corium of the hoof horn might be irreversible, resulting in increasing prevalence of horn lesions with age (Offer et al., 2000; Koenig et al., 2005). Moreover, horn lesions developing in early life are likely to be recurrent in subsequent lactations (Hirst et al., 2002). On the contrary, the risk of infectious lesions decreases with parity (Rodriguez-Lainz et al., 1999; Somers et al., 2005; Holzhauer et al., 2006), suggesting an increase in local immunity with age or culling of older affected cows. Figure 1 shows the percentage of records at each stage of lactation. The percentage of records with hoof lesions was consistent over the productive cycle (Figure 2 ), as expected because lameness is a long-term condition likely to persist over the lactation.

\section{Genetic Parameter Estimation for Hoof Lesions}

The heritability estimates for hoof lesions ranged from 0.01 to 0.09 (Table 3). These estimates are in line with those reported in the literature, which range from 0.01 to 0.17 for different individual hoof lesions based

Table 3. Estimates of variances [additive genetic variance $\left(\sigma_{a}^{2}\right)$, permanent environmental variance $\left(\sigma_{p e}^{2}\right)$, residual variance $\left(\sigma_{e}^{2}\right)$, and total variance $\left(\sigma_{p}^{2}\right)$; values were multiplied by 100$]$ and heritability $\left(h^{2} ;\right.$ SE in parentheses) for hoof lesions ${ }^{1}$

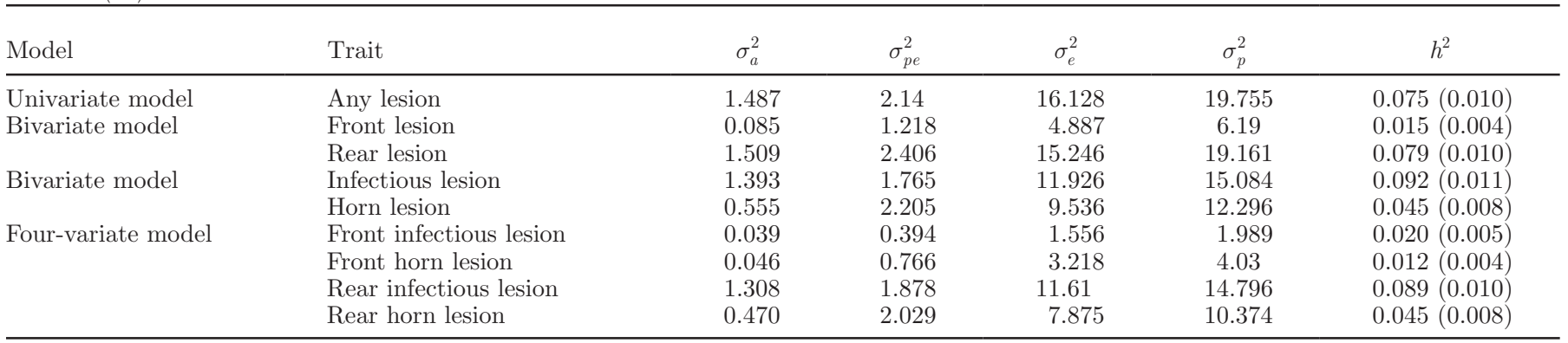

${ }^{1} \mathrm{n}=34,905$ records from 27,179 cows. 
A)

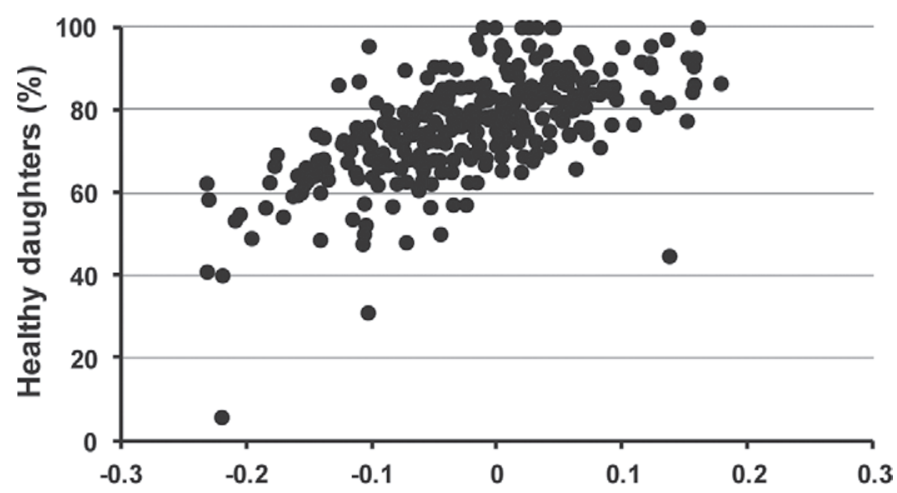

B)

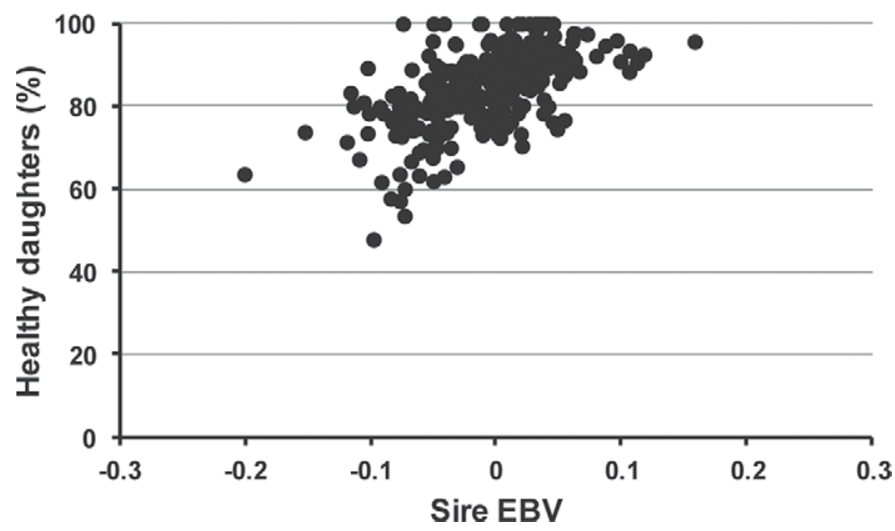

Figure 3. Relationship between sire EBV for resistance to infectious lesions (A) and horn (B) lesions and percentage of healthy daughters $(\mathrm{n}=297$ sires with at least 20 daughters).

on linear models (Swalve et al., 2008; van der Linde et al., 2010; Buch et al., 2011). van der Linde et al. (2010) also estimated a heritability of 0.07 for having at least one hoof lesion. To our knowledge, this is the first study to estimate genetic parameters of hoof lesions separately for the front and rear hooves (most of the studies focus on the rear hooves or make no distinction) and to categorize lesions according to their etiology and pathogenesis into infectious and horn lesions. The heritability was higher for lesions in the rear hooves compared with the front hooves and higher for infectious compared with horn lesions. These differences could be partly explained by the higher prevalence of lesions in the rear than in the front hooves, and the higher prevalence of infectious than horn lesions, as heritability estimates are frequency-dependent when applying linear models to binary data (Gianola, 1982).

The bivariate models showed a positive genetic correlation $(0.551 \pm 0.136)$ between the occurrence of any lesion in the front hooves and any lesion in the rear hooves, but not between the occurrence of any infectious lesion and any horn lesions in any hoof $(0.077 \pm$ 0.110). Similarly, the 4 -variate model (Table 4) showed positive genetic correlations between the occurrence of front and rear infectious lesions, and between front and rear horn lesions, but not between infectious and horn lesions. Other studies have reported positive genetic correlations between different lesions, particularly within horn lesions and within infectious lesions, when considering all hooves together (Buch et al., 2011) or just the rear hooves (van der Waaij et al., 2005; van der Linde et al., 2010). Most of these studies reported low or nonsignificant genetic correlations between different infectious and horn lesions. These results confirm that infectious and horn lesions are different traits, and that within each hoof lesion category, susceptibility is shared between front and rear hooves. This is in accordance with the different etiology and pathogenesis of infectious and horn lesions (Greenough, 2007).

\section{Estimation of Breeding Values}

Despite the low heritabilities for hoof lesion traits, we found large variability in sire EBV (Figure 3) for resistance to both infectious and horn lesions. The mean (SD) of EBV were -0.023 (0.087) and -0.009 (0.049) for infectious and horn lesions, respectively. The average proportion of healthy daughters was $47 \%$ for the 10 sires with the worst EBV and $85 \%$ for the 10 sires with the best EBV for resistance to infectious lesions. The corresponding values for resistance to horn lesions were 76 and $93 \%$ for the 10 sires with the worst and best EBV, respectively.

\section{Phenotypic Effect of Conformation Traits on Hoof Lesions}

Coefficient estimates of each conformation trait obtained from the hoof lesion genetic model [2] are plot-

Table 4. Estimates of genetic correlations between front infectious lesion, front horn lesion, rear infectious lesion, and rear horn lesion from the 4 -variate model (SE in parentheses; $\mathrm{n}=34,905$ records from 27,179 cows)

\begin{tabular}{lccc}
\hline Trait & Front horn lesion & Rear infectious & Rear horn lesion \\
\hline Front infectious & $0.113(0.211)$ & $0.771(0.090)$ & $-0.270(0.143)$ \\
Front horn lesion & & $0.060(0.162)$ & $0.612(0.158)$ \\
Rear infectious & & $0.078(0.107)$ \\
\hline
\end{tabular}


A)

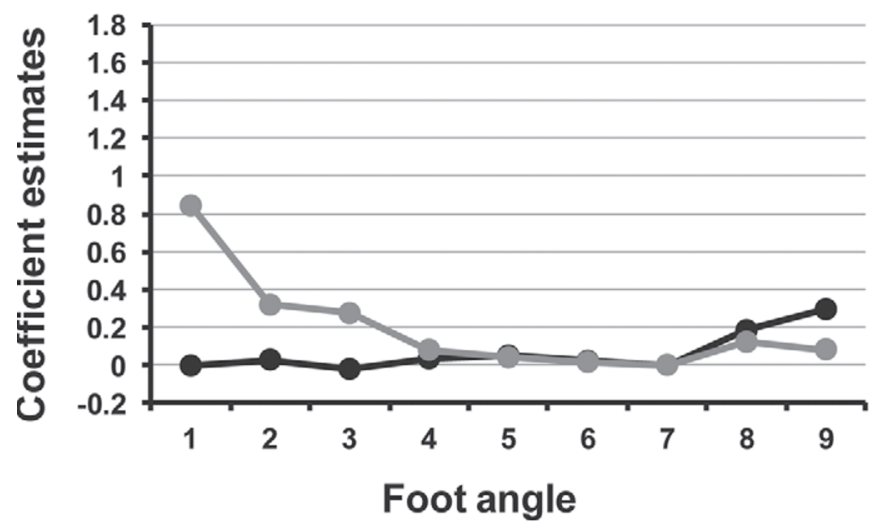

C)

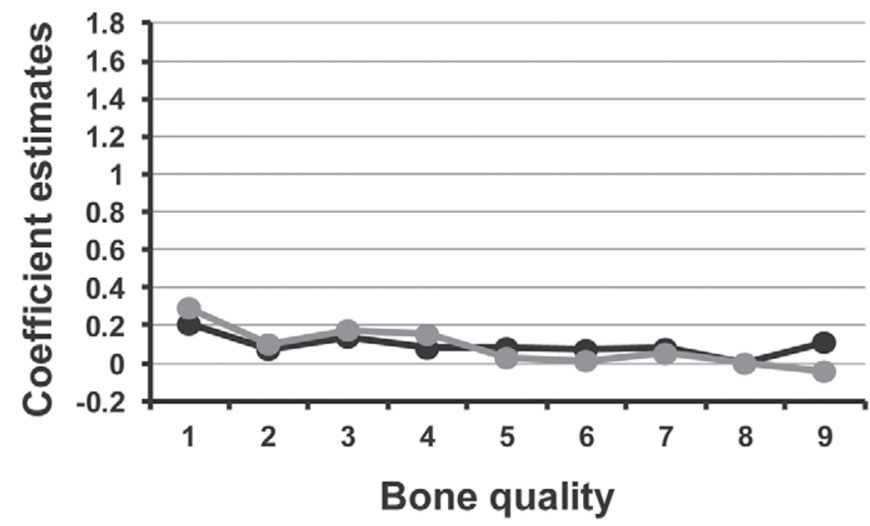

E)

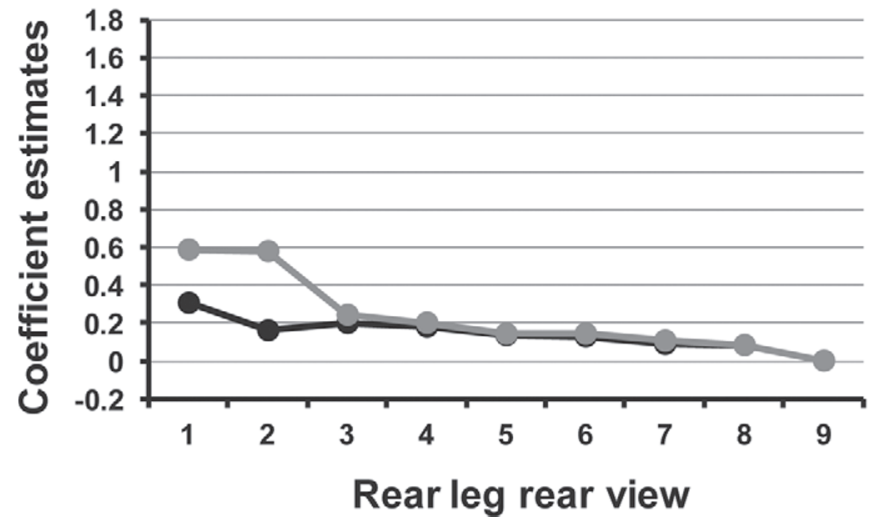

B)

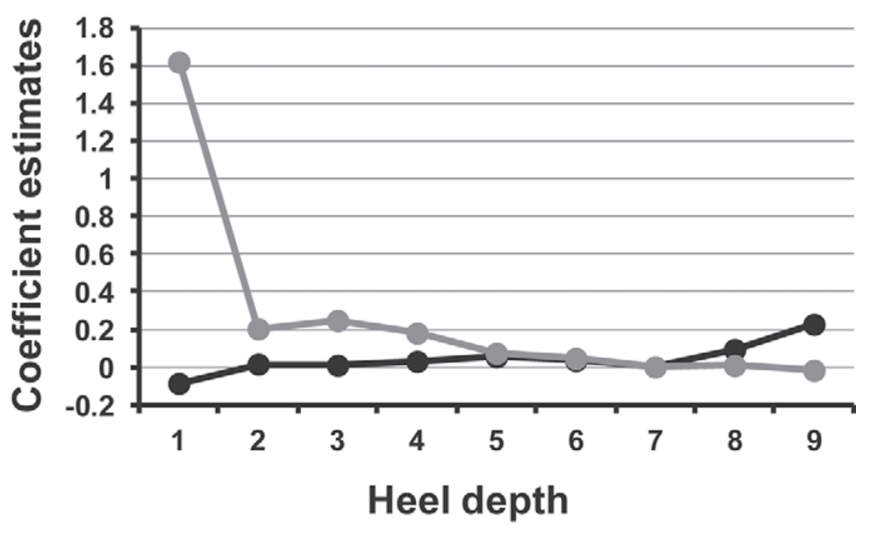

D)

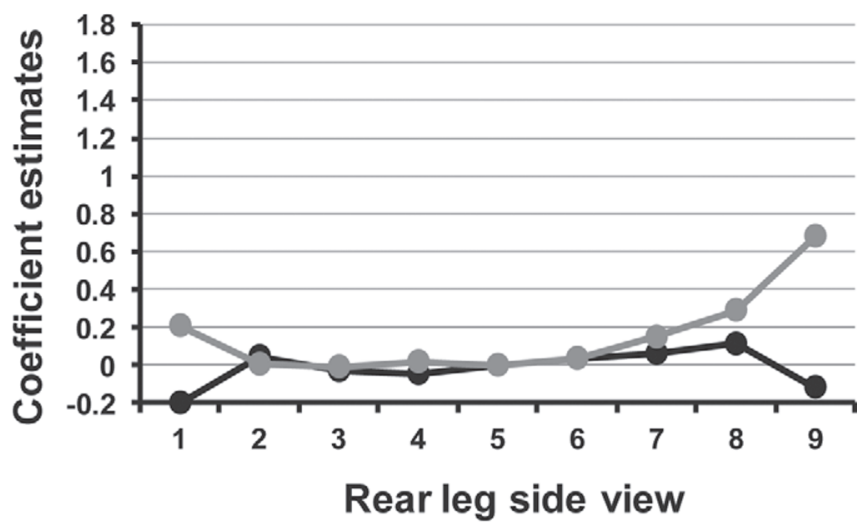

F)

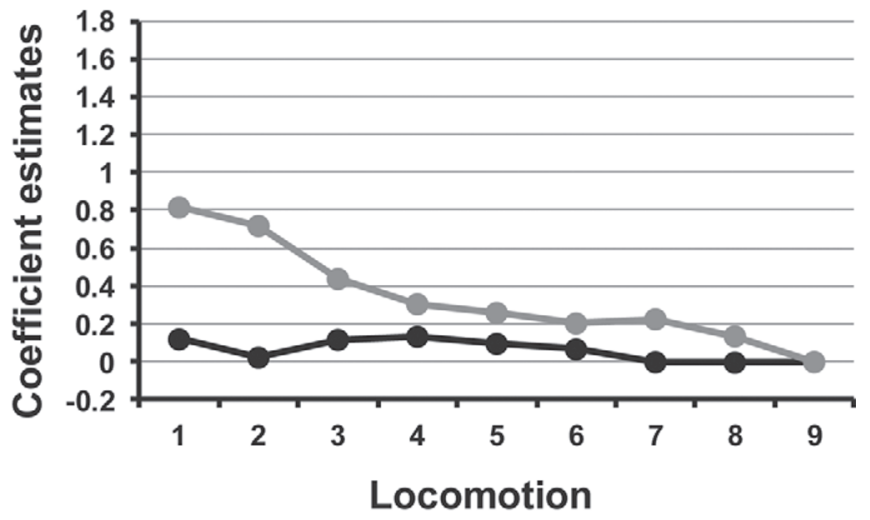

Figure 4. Effect of feet and leg conformation traits and locomotion on infectious (black line) and horn lesions (gray line) by score in primiparous cows. Coefficient estimates are standardized and expressed as deviations from the optimal score (score 7 was considered the optimal score for heel depth).

ted in Figures $4 \mathrm{~A}$ to $4 \mathrm{~F}$. For most of the conformation traits, low scores were phenotypically associated with higher incidence of horn lesions than average, whereas we found no evident effect for infectious lesions. Specifically, low foot angle ( score $=1$ to 3 ) was associated with higher than average incidence of horn lesions (Figure
4A). Additionally, extremely shallow heel depth (score $=1$ ) was associated with a much higher than average incidence of horn lesions (Figure 4B). Regarding rear leg side view, extremely curved legs $($ score $=9$ ) were associated with a higher than average incidence of horn lesions (Figure 4D). Finally, extremely hocked-in legs 
Table 5. Estimates of genetic parameters for infectious lesion, horn lesion, conformation traits, and locomotion from bivariate analyses: heritability $\left(h^{2} ; \mathrm{SE}\right.$ in parentheses) and genetic correlation $\left(\mathrm{r}_{\mathrm{g}} ; \mathrm{SE} \text { in parentheses }\right)^{1}$

\begin{tabular}{lcrr}
\hline & & \multicolumn{2}{c}{$\mathrm{r}_{\mathrm{g}}$} \\
\cline { 3 - 4 } Trait $^{1}$ & $h^{2}$ & Infectious lesion & Horn lesion \\
\hline Infectious lesion & $0.076(0.017)$ & $0.153(0.225)$ & \\
Horn lesion & $0.028(0.011)$ & $-0.182(0.198)$ & $0.217(0.245)$ \\
Foot angle & $0.050(0.015)$ & $-0.051(0.186)$ & $-0.124(0.240)$ \\
Heel depth & $0.070(0.018)$ & $0.222(0.137)$ & $-0.131(0.182)$ \\
Bone quality & $0.223(0.026)$ & $0.267(0.162)$ & $-0.077(0.215)$ \\
Rear leg side view & $0.117(0.022)$ & $-0.394(0.198)$ & $-0.372(0.255)$ \\
Rear leg rear view & $0.041(0.014)$ & $-0.464(0.242)$ & $-0.352(0.329)$ \\
Locomotion & $0.029(0.015)$ & &
\end{tabular}

(score $=1$ to 2 ) and cows with very low score for locomotion ( score $=1$ to 2 ) were associated with a higher incidence of horn lesions than average (Figure 4E and Figures 4F, respectively).

\section{Genetic Parameter Estimation for Hoof Lesions and Conformation Traits}

Heritabilities and genetic correlations for infectious and horn lesions in primiparous cows (Table 5) were in agreement with our previous analyses. The heritability estimates of the conformation traits ranged from 0.03 for locomotion to 0.22 for bone quality. Compared with the heritability estimates used in the routine genetic evaluation in Canada (Interbull, 2011), estimates in this study were slightly lower for most traits. This could be due to the smaller data set used in the present study and differences in data editing procedures.

The genetic correlations between hoof lesions and conformation traits were low to moderate, yet most of the estimates were associated with high standard errors because of a relatively low number of cows with both hoof lesions and conformation records. Swalve et al. (2008) and Uggla et al. (2008) found that most of the genetic correlations between hoof lesions and conformation traits were low or not significant, whereas Onyiro et al. (2008) and van der Linde et al. (2010) obtained higher correlations. Onyiro et al. (2008) found negative genetic correlations for digital dermatitis with locomotion $(-0.67)$ and with bone quality $(-0.21)$. Similarly, van der Linde et al. (2010) found that locomotion was genetically correlated with all the investigated hoof health traits, except for sole hemorrhage and white line disease, with estimates ranging from -0.24 to -0.58 . In addition, van der Linde et al. (2010) found significant genetic correlations between several lesion traits and rear leg rear view, rear leg side view, and foot angle, ranging from -0.32 to 0.25 . Laursen et al. (2009) also found positive genetic correlations between the absence of hoof lesions and locomotion (0.46) and rear leg rear view (0.21), when using hoof health data recorded by veterinarians.

\section{CONCLUSIONS}

Infectious and horn hoof lesions are prevalent in Canada, and genetic selection for hoof health should be incorporated in breeding programs. Although hoof lesions are lowly heritable traits, sufficient genetic variation (as evidenced by large variability in sire EBV) exists for genetic improvement through direct selection in the long term. Infectious and hoof lesions were not genetically correlated, whereas front and rear hoof lesions within each lesion category were moderately correlated. Genetic correlations between hoof lesions and conformation traits and locomotion were low to moderate (albeit associated with high SE), which might explain why indirect selection for improving hoof health by using conformation traits has not been effective so far. Overall, hoof lesion data collected by hoof trimmers have the potential to be used for genetic evaluation of hoof health; therefore, standardization of hoof lesion data collection should be encouraged. Moreover, standardization of hoof lesion data collection is fundamental to monitor the incidence of hoof lesions and its association with management practices.

\section{ACKNOWLEDGMENTS}

The authors are grateful to the hoof trimmers who participated in this study. This project was funded by DairyGen council of Canadian Dairy Network (Guelph, ON, Canada), Natural Sciences and Engineering Research Council of Canada (Ottawa, ON, Canada), and Alberta Milk (Edmonton, AB, Canada). Núria Chapinal was supported by a Beatriu de Pinós postdoctoral grant from the Generalitat de Catalunya. 


\section{REFERENCES}

Amory, J. R., Z. E. Barker, J. L. Wright, S. A. Mason, R. W. Blowey, and L. E. Green. 2008. Associations between sole ulcer, white line disease and digital dermatitis and the milk yield of 1824 dairy cows on 30 dairy cow farms in England and Wales from February 2003-November 2004. Prev. Vet. Med. 83:381-391.

Barker, Z. E., J. R. Amory, J. L. Wright, S. A. Mason, R. W. Blowey and L. E. Green. 2009. Risk factors for increased rates of sole ulcers, white line disease, and digital dermatitis in dairy cattle from twenty-seven farms in England and Wales. J. Dairy Sci. 92:1971-1978.

Booth, C. J., L. D. Warnick, Y. T. Gröhn, D. O. Maizon, C. L. Guard, and D. Janssen. 2004. Effect of lameness on culling in dairy cows. J. Dairy Sci. 87:4115-4122.

Buch, L. H., A. C. Sørensen, J. Lassen, P. Berg, J. Å. Eriksson, J. H. Jakobsen, and M. K. Sørensen. 2011. Hygiene-related and feedrelated hoof diseases show different patterns of genetic correlations to clinical mastitis and female fertility. J. Dairy Sci. 94:1540-1551.

Cook, N. B., and K. V. Nordlund. 2009. The influence of the environment on dairy cow behaviour, claw health and herd lameness dynamics. Vet. J. 179:360-369.

Cramer, G., K. D. Lissemore, C. L. Guard, K. E. Leslie, and D. F. Kelton. 2008. Herd- and cow-level prevalence of foot lesions in Ontario dairy cattle. J. Dairy Sci. 91:3888-3895

Cramer, G., K. D. Lissemore, C. L. Guard, K. E. Leslie, and D. F Kelton. 2009. Herd-level risk factors for seven different foot lesions in Ontario Holstein cattle housed in tie stalls or free stalls. J. Dairy Sci. 92:1404-1411.

Gianola, D. 1982. Theory and analysis of threshold characters. J. Anim. Sci. 54:1079-1096.

Greenough, P. R. 2007. Bovine Laminitis and Lameness: A Hands-On Approach. W. B. Saunders Company, Edinburgh, UK.

Hernández, J., J. K. Shearer, and D. W. Webb. 2001. Effect of lameness on the calving-to-conception interval in dairy cows. J. Am. Vet. Med. Assoc. 218:1611-1614.

Hirst, W. M., R. D. Murray, W. R. Ward, and N. P. French. 2002. A mixed-effects time-to-event analysis of the relationship between first-lactation lameness and subsequent lameness in dairy cows in the UK. Prev. Vet. Med. 54:191-201.

Holzhauer, M., C. Hardenberg, C. J. Bartels, and K. Frankena. 2006. Herd- and cow-level prevalence of digital dermatitis in the Netherlands and associated risk factors. J. Dairy Sci. 89:580-588.

Interbull. 2011. Description of national genetic evaluation systems (Canada). Accessed Jul. 31, 2012. http://www-interbull.slu.se/ national_ges_info2/framesida-ges.htm.

Koenig, S., A. R. Sharifi, H. Wentrot, D. Landmann, M. Eise, and H. Simianer. 2005. Genetic parameters of claw and foot disorders estimated with logistic models. J. Dairy Sci. 88:3316-3325.

Laursen, M. V., D. Boelling, and T. Mark. 2009. Genetic parameters for claw and leg health, foot and leg conformation, and locomotion in Danish Holsteins. J. Dairy Sci. 92:1770-1777.

Madsen, P., and J. Jensen. 2008. An User's Guide to DMU: A Package for Analyzing Multivariate Mixed Models. Version 6, release 4.7. Danish Institute of Agricultural Sciences, Tjele, Denmark.

Manske, T., J. Hultgren, and C. Bergsten. 2002. Prevalence and interrelationships of hoof lesions and lameness in Swedish dairy cows. Prev. Vet. Med. 54:247-263.

Meléndez, P., J. Bartolome, L. F. Archbald, and A. Donovan. 2003. The association between lameness, ovarian cysts and fertility in lactating dairy cows. Theriogenology 59:927-937.
Negussie, E., I. Strandén, and E. A. Mäntysaari. 2008. Genetic analysis of liability to clinical mastitis, with somatic cell score and production traits using bivariate threshold-linear and linear-linear models. Livest. Sci. 117:52-59.

Neuenschwander, T. F. O. 2010. Studies on disease resistance based on producer-recorded data in Canadian Holsteins. PhD thesis. University of Guelph, Guelph, ON, Canada.

Offer, J. E., D. McNulty, and D. N. Logue. 2000. Observations of lameness, hoof conformation and development of lesions in dairy cattle over four lactations. Vet. Rec. 147:105-109.

Onyiro, O. M., L. J. Andrews, and S. Brotherstone. 2008. Genetic parameters for digital dermatitis and correlations with locomotion, production, fertility traits, and longevity in Holstein-Friesian dairy cows. J. Dairy Sci. 91:4037-4046.

Phillips, C. J. C. 2002. Cattle Behaviour and Welfare. 2nd ed. Blackwell Science Ltd., Oxford, UK.

Rajala-Schultz, P. J., and Y. T. Gröhn. 1999. Culling of dairy cows. I Effects of diseases on culling in Finnish Ayrshire cows. Prev. Vet. Med. 41:195-208.

Rodriguez-Lainz, A., P. Melendez-Rentamal, D. W. Hird, D. H. Read, and R. L. Walker. 1999. Farm- and host-level risk factors for papillomatous digital dermatitis in Chilean dairy cattle. Prev. Vet. Med. 42:87-97.

Snell, E. J. 1964. A scaling procedure for ordered categorical data. Biometrics 20:592-607.

Sogstad, A. M., T. Fjeldaas, O. Osteras, and K. P. Forshell. 2005 Prevalence of claw lesions in Norwegian dairy cattle housed in tie stalls and free stalls. Prev. Vet. Med. 70:191-209.

Somers, J. G., K. Frankena, E. N. Noordhuizen-Stassen, and J. H. Metz. 2003. Prevalence of claw disorders in Dutch dairy cows exposed to several floor systems. J. Dairy Sci. 86:2082-2093.

Somers, J. G., K. Frankena, E. N. Noordhuizen-Stassen, and J. H. M. Metz. 2005. Risk factors for interdigital dermatitis and heel erosion in dairy cows kept in cubicle housing in the Netherlands. Prev. Vet. Med. 71:23-34

Swalve, H. H., H. Alkhoder, and R. Pijl. 2008. Estimates of breeding values for sires based on diagnoses recorded at hoof trimming: Relationships with EBV for conformation traits. Interbull Bull. 38:87-90.

Uggla, E., J. H. Jakobsen, C. Bergsten, J.-A. Eriksson, and E. Strandberg. 2008. Genetic correlations between claw health and feet and leg conformation traits in Swedish dairy cows. Interbull Bull. 38:91-95.

van der Linde, C., G. de Jong, E. P. C. Koenen, and H. Eding. 2010 Claw health index for Dutch dairy cattle based on claw trimming and conformation data. J. Dairy Sci. 93:4883-4891.

van der Waaij, E. H., M. Holzhauer, E. Ellen, C. Kamphuis, and G. de Jong. 2005. Genetic parameters for claw disorders in Dutch dairy cattle and correlations with conformation traits. J. Dairy Sci. 88:3672-3678.

Warnick, L. D., D. Janssen, C. L. Guard, and Y. T. Grohn. 2001. The effect of lameness on milk production in dairy cows. J. Dairy Sci 84:1988-1997.

Whay, H. R.. D. C. Main, L. E. Green, and A. J. Webster. 2003. Assessment of the welfare of dairy cattle using animal-based measurements: Direct observations and investigation of farm records. Vet. Rec. 153:197-202. 